\title{
A Novel Surgical Approach for the Reconstruction of Critical-Size Mandibular Defects using Calcium Sulphate/Hydroxyapatite Cement, BMP-7 and Mesenchymal Stem Cells - Histological Assessment
}

\author{
Randa Alfotawi ${ }^{1,2}$, Ashraf F Ayoub ${ }^{2^{*}}, \mathrm{~K}$ Elizabeth Tanner ${ }^{3}$, Matthew J Dalby ${ }^{4}$, \\ Kurt B Naudi ${ }^{5}$ and Jeremy McMahon ${ }^{6}$ \\ $1 \mathrm{~S}$. Registrar in Oral and Maxillofacial Department Dental Faculty, King Saud University, Saudi \\ Arabia \\ 2 Professor of Oral \& Maxillofacial Surgery, MVLS College, University of Glasgow, UK \\ 3 Professor of Biomedical Materials, School of Engineering, University of Glasgow, UK. \\ 4 Professor, Centre for Cell Engineering, MVLS college, University of Glasgow, UK \\ 5 Clinical Lecturer, Oral Surgery, Glasgow University Dental Hospital \& School, UK \\ 6 Consultant of Oral \& Maxillofacial Surgery, Southern General Hospital, Glasgow, UK
}

\begin{abstract}
A novel construct has been developed to induce bone formation within a pedicle muscle flap. A critical size defect $\left(20 \times 15 \mathrm{~mm}^{2}\right)$ was created in the mandible of ten rabbits. The masseter muscle was adapted to fill the surgical defect and a combination of calcium sulphate/hydroxyapatite cement (CERAMENT ${ }^{\text {TM ISPINE }}$ SUPPORT), BMP-7 and rabbits' mesenchymal stromal cells (rMSCs) was injected into the muscle tissue. Bone regeneration was evaluated 3 months after surgery. Limited areas of bone formation anatomically bridged the defect, despite the new bone forming throughout the muscle and within the connective tissue surrounding the remnants of the cement. The bone was thicker in the bucco-lingual direction compared to the contra lateral (non-operated) side. Quantitative histomorphometry assessment showed that the average bone surface area was $21.2 \pm 6.0 \mathrm{~mm}^{2}$, this was significantly greater than that of the contra-lateral nonoperating control side. The calculated amounts of residual cement and soft tissue or spaces were $20 \pm 12 \%$ and $41 \pm 10 \%$, respectively. The average mineral apposition rate (MAR) was $1.92 \mu \mathrm{m} /$ day. The findings demonstrated the remarkable potential of the use of local muscle flaps for injectable bio-cement loaded with BMP and seeded with rMSCs to induce bone formation for the reconstruction of bony defects.
\end{abstract}

Keywords: bone, Bioengineering, scaffolding, calcium sulphate
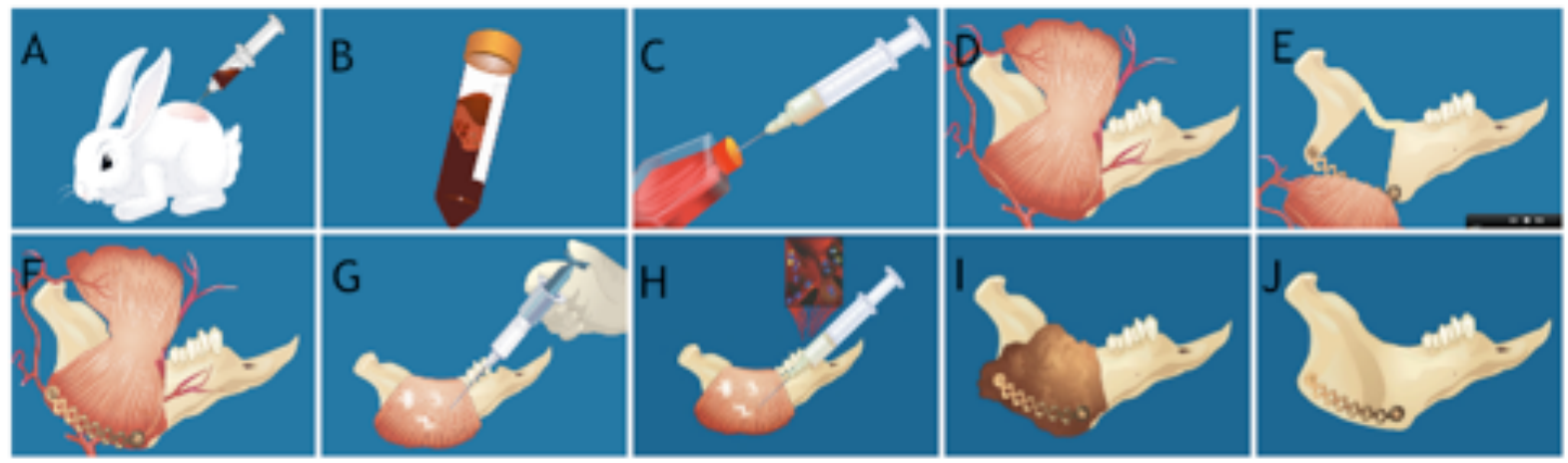

Figure 1 Summary of the in-vitro and in-vivo research protocol. A) bone marrow aspiration from the posterior iliac crest; B) bone marrow aspirate ready for rMSCs isolation, expansion and culture; C) Cell suspension prepared for re-implantation in vivo, D) Dissection of the masseter muscle into superficial and deep layer; E) Creation of critical size defect of the ramus of the mandible; F) Adaptation of the masseter muscle into the defect and around the titanium plate; $G$ ) injection of the bio-cement; I) Osseo-induction under the effect of cement, BMP-7 and rMSCs; J) Ideal scenario of bone regeneration after 3 months.

*Author to whom correspondence is addressed 


\section{INTRODUCTION}

Autogenous grafts and allografts are the most widely used techniques for bone grafting. However, these techniques have drawbacks when used for the reconstruction of critical sized bone defects, including the limited availability, the donor site morbidity 1,2 and the reported high failure rate rat. $^{3,4}$. These limitations have inspired the search for innovative techniques for bone regeneration. Tissue engineering and regenerative medicine (TE/RM) strategies have demonstrated significant potential to develop substitutes that promote endogenous repair mechanisms and functional regeneration through delivery of signals that stimulate host cells to populate a tissue defect and induce the synthesis of a robust extracellular matrix ${ }^{5}$. Successful tissue engineering is dependent on the vascularisation of three-dimensional tissue constructs $^{6}$. Tissue regeneration carries a combination of physical and biochemical cues through the scaffold structures. ${ }^{7}$ The use of osteoprogenitor cells and/or bone morphogenic protein (BMP) has been successful in the reconstruction of segmental mandibular defects in human trials ${ }^{8-10}$. In contrast, there was a $13.9 \%$ failure rate in cases where BMP alone was used to reconstruct large complex bone defects in the maxillofacial region in human trials ${ }^{11}$. Insufficient vascularity has always been the main obstacle in the reconstruction of large bony defects. Therefore, several strategies have been considered to improve the vascularity of the recipient site which included the use of vascular endothelial growth factors (VEGF), angiogenic proteins and hypoxia induced factor-1 $\alpha^{12-14}$. The advanced development of growth factor delivery strategies to ensure the sustained release of one or more cytokines and enhancement of the vascular bed have shown promising results with regards to the regeneration of large bony defects ${ }^{15}$.

Surgeons have investigated other methods to tackle the problem of vascularity at the recipient site by rotating a pedicled muscle flap, due to its adequate and reliable blood supply, to the surgical defect to induce bone formation ${ }^{16-18}$. Muscle has the propensity to form bone; it has been shown that the inclusion of alloplastic material into skeletal muscle induces bone formation in vivo ${ }^{19-21}$. Recent in vivo studies have shown that the structure of the alloplastic materials should exhibit microporosity and macroporosity to induce bone formation ${ }^{21,22}$. Osteoinduction on the other hand does not seem to be substantially related to the material chemistry, as various types of bioceramic compositions, including calcium phosphates, bioglasses, titanium oxides and alumina, have induced bone formation ${ }^{23-25}$. Successful bone formation within tissue using BMP has been reported ${ }^{26}$. The release of cytokines has been noted when BMPs were mixed with bioceramic based bone cement, these in turn promoted the proliferation and differentiation of mesenchymal stem cells ${ }^{27-28}$.

The rational of this study is that a pedicled muscle provides a rich blood supply, essential for bone regeneration. We tested the hypothesis that the injection of a biocement loaded with BMP into a pedicled muscle flap would induce bone formation. The second hypothesis was that the injection of the cement (calcium sulphate/hydroxyapatite,

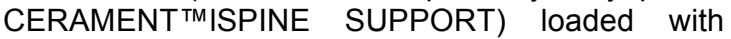
BMP-7 and seeded with the mesenchymal stromal cells (rMSCs) into a muscle flap would induce enough bone formation for the reconstruction of a mandibular defect in one stage.

\section{MATERIALS AND METHODS}

This study was carried out on 10 New Zealand rabbits as they provide a suitable model for this preclinical study. Approval was obtained from the UK Home Office under the Animals (Scientific Procedures) Act 1986. Rabbit bone marrow aspiration, rMSCs isolation, culture, characterization and assessment of the cell-cement interaction followed a standard protocol ${ }^{30}$. The cement used in this study was injectable and commercially available (CERAMENT TMISPINE SUPPORT, Bone Support $A B$, Lund, Sweden) composed of $60 \%$ calcium sulphate, $40 \%$ hydroxyapatite powder and a liquid phase of water and an opacifier (lohexol).

\subsection{Surgical procedure}

The animals were obtained from a designated farm and kept in a dedicated animal house under veterinary supervision in the small animal research facilities. Each case was premeditated with $12.5 \mu \mathrm{g}$ Fentanyl transdermal patch applied the afternoon prior to surgery. Fentanyl citrate and Fluanisone (Hypnorm, $0.5 \mathrm{ml} / \mathrm{kg}$ ) were given intramuscularly 30 minutes before surgery and Midazolam (2mg/kg) was administered intravenously at induction. The animals received endotracheal intubation and were given Insflurane, nitrous oxide, and oxygen. Oxygen saturation was monitored throughout the surgical procedure. A $2 \mathrm{~cm}$ right submandibular skin incision was performed to expose the angle of the mandible. A straight ramus osteotomy was performed using a drill and carbide burr, with the first cut made 3 to 5 millimetres posterior to the last molar tooth and the second cut made $10 \mathrm{~mm}$

Table I. The protocol of administration of fluorochrome for bone labeling.

\begin{tabular}{|l|l|l|l|l|}
\hline Bone label & Dose & Concentration & $\begin{array}{l}\text { Route of } \\
\text { administration }\end{array}$ & $\begin{array}{l}\text { Day of administration from day } \\
\text { of surgery }\end{array}$ \\
\hline $\begin{array}{l}\text { Oxytetracyclin (Enegemycin, MSD } \\
\text { Animal Health, UK) }\end{array}$ & $0.5 \mathrm{mg} / \mathrm{kg}$ & $20 \mathrm{mg} / \mathrm{ml}$ & S/C & 4 weeks \\
\hline Calcein blue (Sigma Aldrich, UK) & $0.2 \mathrm{mg} / \mathrm{kg}$ & $50 \mathrm{mg} / \mathrm{ml}$ & $\mathrm{S} / \mathrm{C}$ & 8 weeks \\
\hline Alizarin red (Sigma Aldrich, UK & $0.5 \mathrm{mg} / \mathrm{kg}$ & $30 \mathrm{mg} / \mathrm{ml}$ & $\mathrm{S} / \mathrm{C}$ & 11 weeks \\
\hline
\end{tabular}


Table II. Qualitative descriptive parameters for assessment of H\&E stained decalcified sections.

\begin{tabular}{|c|c|c|c|}
\hline \multicolumn{4}{|c|}{ Description } \\
\hline $\begin{array}{l}\text { Quality of } \\
\text { union }\end{array}$ & $\begin{array}{l}\text { Cortex } \\
\text { development }\end{array}$ & $\begin{array}{l}\text { Residual } \\
\text { scaffold } \\
\text { material }\end{array}$ & $\begin{array}{l}\text { Inflammatory } \\
\text { response }\end{array}$ \\
\hline $\begin{array}{l}\text { No sign of } \\
\text { fibrous or } \\
\text { other union } \\
\text { Fibrous union } \\
\text { Osteochondral } \\
\text { union } \\
\text { Bone union } \\
\text { Bone union } \\
\text { with } \\
\text { reorganization } \\
\text { of cortices }\end{array}$ & $\begin{array}{l}\text { Non present } \\
\text { in the defect } \\
\text { Densification } \\
\text { of borders } \\
\text { Recognizable } \\
\text { formation } \\
\text { Intact cortices } \\
\text { but not } \\
\text { complete } \\
\text { Complete } \\
\text { formation of } \\
\text { normal } \\
\text { cortices }\end{array}$ & $\begin{array}{l}\text { Large amount } \\
\text { visible } \\
\text { Moderate } \\
\text { amount of } \\
\text { scaffold } \\
\text { Small amount } \\
\text { of scaffold } \\
\text { No residual } \\
\text { scaffold and } \\
\text { some marrow } \\
\text { element } \\
\text { Normal } \\
\text { marrow } \\
\text { elements }\end{array}$ & $\begin{array}{l}\text { Severe } \\
\text { Severe/mode } \\
\text { rate } \\
\text { Moderate } \\
\text { Mild } \\
\text { No response }\end{array}$ \\
\hline
\end{tabular}

posterior to the first cut across the ascending border of the ramus of the mandible, and extending downward to the inferior border of the angle of the mandible creating a surgical defect of $20 \times 15 \mathrm{~mm}^{2}$. The upper border of the mandible was kept intact. To maintain the stability of the mandible a titanium plate was applied at the inferior border of the mandible and secured in place by two screws on each side of the defect. The deep layer of the masseter muscle was dissected, reflected from its insertion, pedicled and adapted into the defect created in the ramus of the mandible. The cement, $1.5 \mathrm{ml}$ CERAMENT ${ }^{\mathrm{TM}}$ |SPINE SUPPORT was mixed with $0.4 \mathrm{mg} / \mathrm{ml}$ BMP-7 (Op-1 Osigraft, Stryker Biotech, Ireland) and the mixture was injected into the masseter muscle flap. Once the material set, which took about 10 minutes, the prepared rMSCs suspension which contained three and half million cells was injected around the cement (Figure 1). This two injection protocol was based on our previous laboratory studies to maximize the survival of the cells ${ }^{29}$. The surgical site was sutured in layers, the animals followed a standard postoperative protocol to minimize infection and to reduce postoperative pain. The surgical site was inspected and cleaned daily. Animals were kept on soft food for 3-4 days following surgery. Prophylactic antibiotics cover was given using Oxy $10 \%$ injon of $0.2 \mathrm{~m} / \mathrm{kg}$. Aftor full recovery, the rabbit was transferred to the normal holding cage and $10 \mathrm{ml}$ saline was given S/C to avoid dehydration. The activity of the rabbit was monitored on a daily basis, as was the site of the operation for any bleeding or signs of infection. A mushy diet was offered to the animals, nonsteroidal anti-inflammatory $0.16 \mathrm{ml}$ Metacam $(0.2 \mathrm{mg} / \mathrm{kg})$ was given subcutaneous on the first 24 hours and 2nd post-operative day.

To assess the magnitude of bone apposition, under sedation the rabbits were injected with bone labeling materials (table I) following a standard protocol (34). The rabbits were euthanatized three months following surgery by an overdose of IV sodium pentobarbitone $(140 \mathrm{mg} / \mathrm{kg})$. The mandibles were explanted and the surgical sites were examined. Samples were subjected to a comprehensive radiological evaluation ${ }^{30}$ and then prepareutorhistological assessment.

\subsection{Histological assessments:}

The decalcified tissue blocks were embedded in paraffin wax and $5 \mu \mathrm{m}$ sections were prepared and stained with Hematoxylin \& Eosin (H\&E). Three decalcified histology slides (H\&E) per defect were examined and quality of the bone regeneration, the degree of cortex development, the magnitude of the remaining undegraded cement and associated inflammatory cells were evaluated (Table I). Bone regeneration, quality and graft incorporation were scored using a semi-quantitative scale (Table II) ${ }^{31}$. The specimens assigned for undecalcified examination were dehydrated in graduated ethyl alcohol solutions, infiltrated and embedded in acrylic resin (Technovit 7200 VLC, EXAKT, Kulzer \& Co $\mathrm{GmbH}$, Germany) and photopolymerized. From each section, 2 slides were prepared for undecalcified section using Goldner's trichrome and Sanderson's-Van Gieson stain, while one section was kept unstained for fluorochrome analysis. The percentage of regenerated tissue, residual cement, and fibrous/muscular tissue was estimated ${ }^{22}$. The values were compared to the control non-operated side. One control specimen was prepared from the

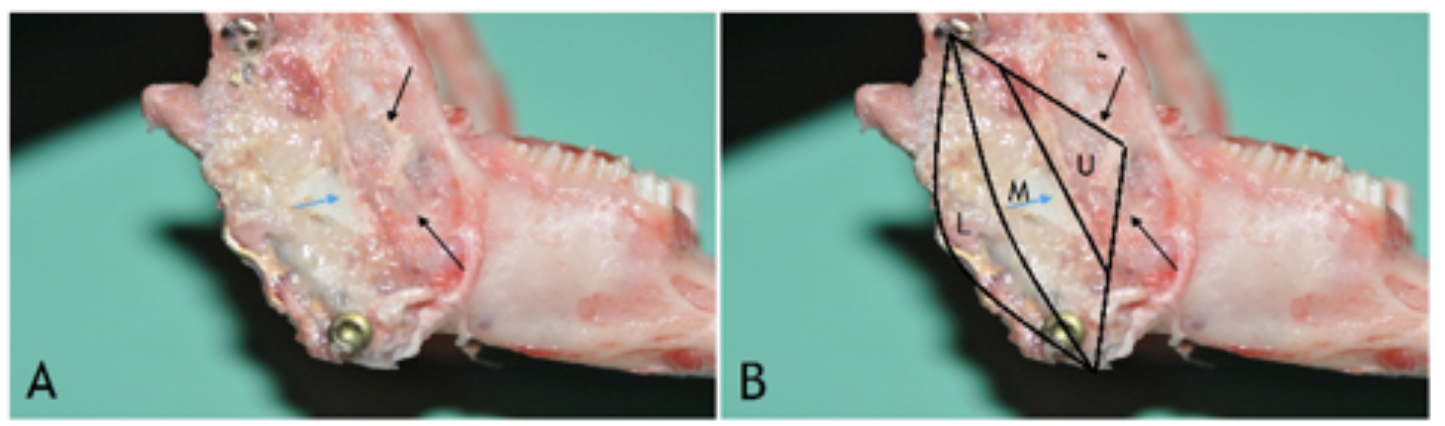

Figure 2. The explanted mandible before histological assessment, the black arrows in figure A point to the area of bone regeneration which was examined under the microscope. Figure B shows the upper third $(U)$, the middle third ( $M$, marked by a blue arrow), and the lower third $(\mathrm{L})$ that were subjected to decalcified and undecalcified histological assessment. 


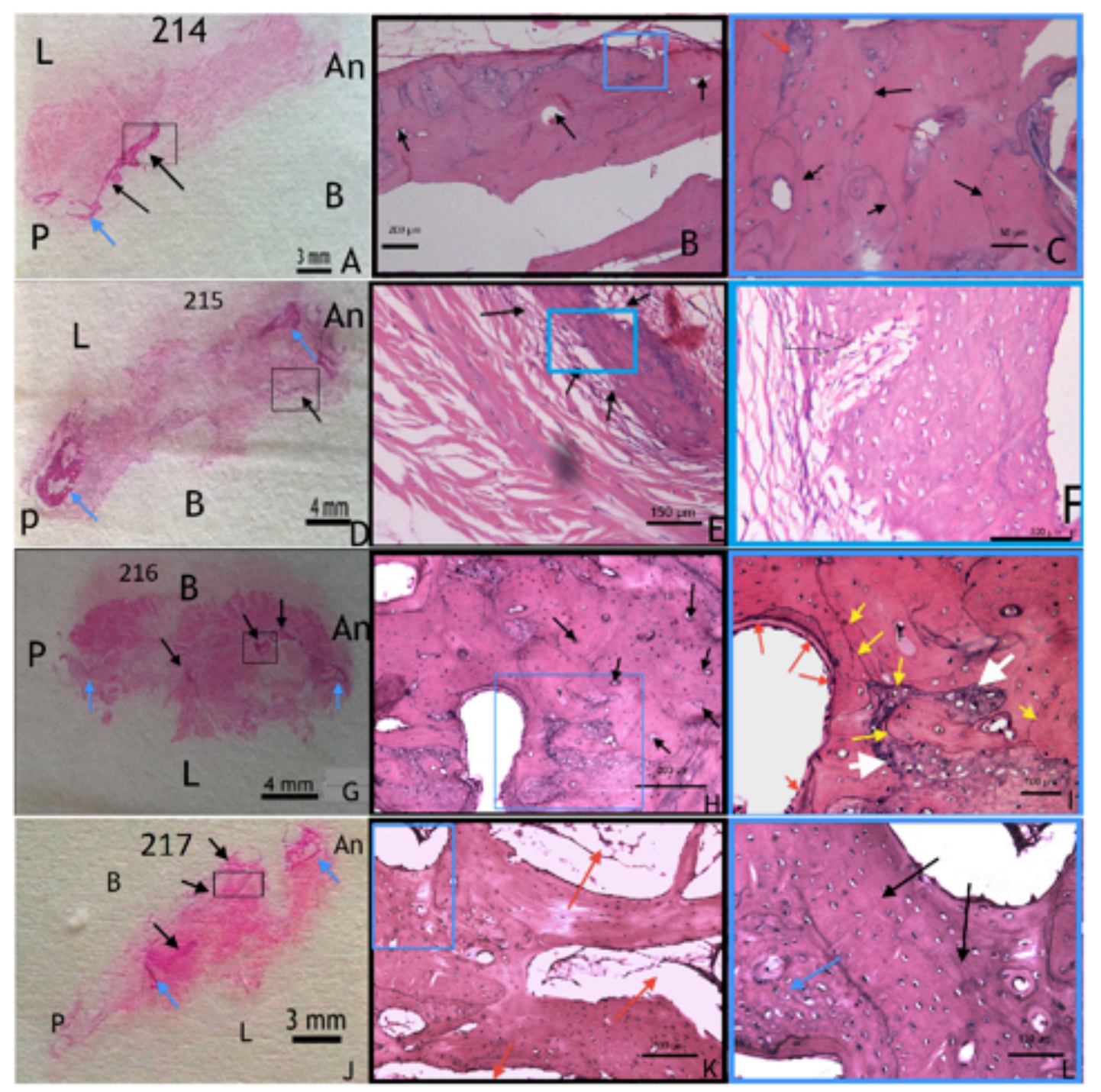

Figure 3. Photomicrographs of decalcified sections stained with H\&E demonstrating areas of bone regeneration at the surgical defect in four cases, each case is represented by a row of images, with increasing magnification levels. An, P, $L$ and $B$ indicate the anterior, proximal, lingual and buccal borders of the defect. Sections $A, D, G$ and $\mathrm{J}$ (left hand column) show the overall view for the whole defect between the blue arrows. Images B, E, H and $\mathrm{K}$ at $200 \mu \mathrm{m}$ magnification show the characteristics of bone regeneration (black arrow). Images C, F, I, L are at a higher magnification $(100 \mu \mathrm{m})$ of the blue boxed areas on sections $\mathrm{B}, \mathrm{E}, \mathrm{H}$ and $\mathrm{K}$. In all the cases the regenerated bone was a mixture of mature and immature bone. Reversal lines (black arrows) were seen in some cases (section $\mathrm{C}$ ) which indicate the remodelling process.

bone of the non-operated contra-lateral side of each rabbit.

Mean values for surface area, percentage and the SD of bone, residual cement and soft tissue/ marrow for the ten experimental samples were calculated.

The percentage bone in each field was calculated according to equation 1 :

Percentage bone $=\frac{\sum\left(a_{f}-\left(a_{m s}+a_{f t}\right)\right)}{\sum a_{f}} \times 100 \% \quad$ [Eqn 1]

where $a_{f}$ is area of the microscopic field, $a$ is area of marrow space and $a_{s t}$ is area of the soft tissue.

The Mineral Apposition rate (MAR) of bone ingrowth between 8 and 12 weeks within the injectable calcium sulphate/HA cement implants was determined using Equation $2^{33}$.

$$
\operatorname{MAR}=\frac{0.74 \sum_{x=1}^{x=n} D_{x}}{n \times t}
$$

[Eqn 2]

where $D_{x}$ is the distance between two fluorochrome labels in micrometers for each measurement, $n$ is the number of measurements and $t$ is the time interval in days between the administration of the fluorochromes. These measurements were performed on both operated and non-operated sides. 


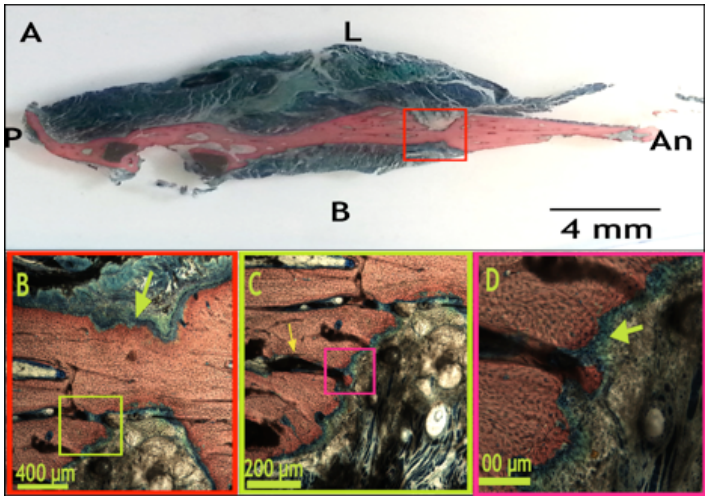

Figure 4. Undecalcified Sanderson's-Van Gieson stained sections of areas of bone regeneration at the created surgical defect. A, shows the overall view of the surgical defect and the regenerated bone (red box) that extended from the anterior margin (An) to the posterior border $(P)$ of the defect, (scale bar $=4 \mathrm{~mm}$ ). B) The interface between the native and the new generated bone, (scale bar = $400 \mu \mathrm{m})$. C) Higher magnification at the area of interest (green box of section B) which shows close relation between the cement (black) periosteal fibrous tissue (green), muscle fibres (scale bar = $200 \mu \mathrm{m})$. D) Higher magnification of the area within the pink box of image $C$ which shows the regeneration of periosteum (arrow) covering the newly formed bone adjacent to the residual cement (black areas) (scale bar $=100 \mu \mathrm{m})$.

\section{Results}

All the rabbits completed the term of the study; the surgical procedure did not affect the welfare of the animals. Clinically, fibrous tissue was found around the titanium fixation plate. Bone overgrowth was observed at the area around the proximal (posterior) screw in most of the cases. A thin layer of regenerated hard tissue appeared between the muscle tissues that emerged from the inferior aspect of the graft. An area of whitish rubbery mass was observed between the muscle fibres of the non-degraded remnants of the injected cement, thus the hydroxyapatite phase interspersed with the surrounding soft tissue (Figure 2).
Examination of both decalcified and undecalcified sections confirmed that the magnitude of bone regeneration in the defect was varied through the sections (Figures 3 and 4) when compared to the control non-operated side (Figure 5). Regenerated bone was noted at the borders and at the centre of the defect. Only few sections showed complete bridging of the surgical defect with the regenerated bone. Woven bone was detected at the interface when union existed between the regenerated tissue and the surrounding native bone. (Figure 6A). The regenerated bone showed active remodelling with the presence of both lamellar and woven bone, multiple reversal lines and the presence of osteoclasts (Figure 6B). Figure 7 shows the regenerated buccal and lingual cortices and the intermediate trabecular pattern of the newly formed bone (Figure 7). The semi-quantitative examination revealed that five of the 10 cases showed development of at least one cortex; both cortices were noted in three cases. Residual cement was seen in half of the examined cases; however, there were empty spaces around the newly formed bone and between the loose connective tissue which might be an area of bone cement that was removed during decalcification. The residual cement was cellular and showed mild (less than 20 cells) to moderate (more than 20 cells) lymphocytic cell infiltration. On the other hand, all the examined slides showed that at least $20 \%$ of the space was filled with marrow fibrosis or collagen fibres. Areas of calcified tissue were also seen within the residual part of the cement (Figure 8).

\subsection{Histomorphometry of the Decalcified Sections}

The mean percentage bone, residual cement, and soft tissue and marrow spaces for the examined cases are summarized in table 4 . The mean of the bone surface area was $21.2 \% \pm 6$ which was estimated to be $3.6 \%$ more than the surface area in the non-operated side. Whereas, the estimated percentage of bone regeneration, residual cement and soft tissue/marrow spaces from all the examined slides for all cases were $37 \% \pm 15 \%, 20$ $\pm 12 \%$ and $41 \pm 10 \%$ respectively as shown in table 5 and illustrated in figure 9.

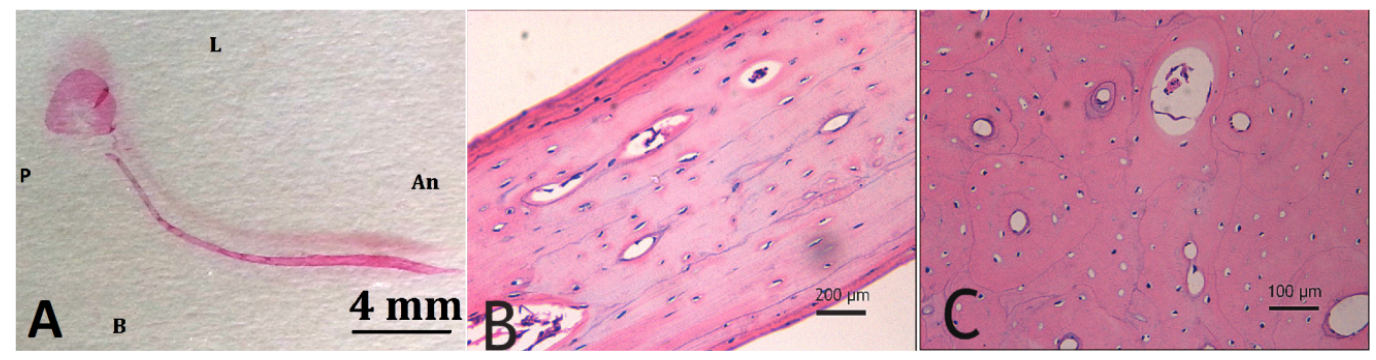

Figure 5. Photomicrographs of H\&E stained decalcified section of the non-operated side. A) A sagittal section through the ramus of the mandible (scale bar $=3 \mathrm{~mm}$ ). figure B shows a well developed highly vascular lamellar type of bone, osteocytes in their lacunae arranged parallel to bone lamella surrounded with osteoblasts on the outer surface (scale bar $=200 \mu \mathrm{m}$ ). Figure $\mathrm{C}$ shows bone osteons; the cells in the lacunae were smaller than in the contra lateral experimental sites (scale bar $=100 \mu \mathrm{m}$ ). 


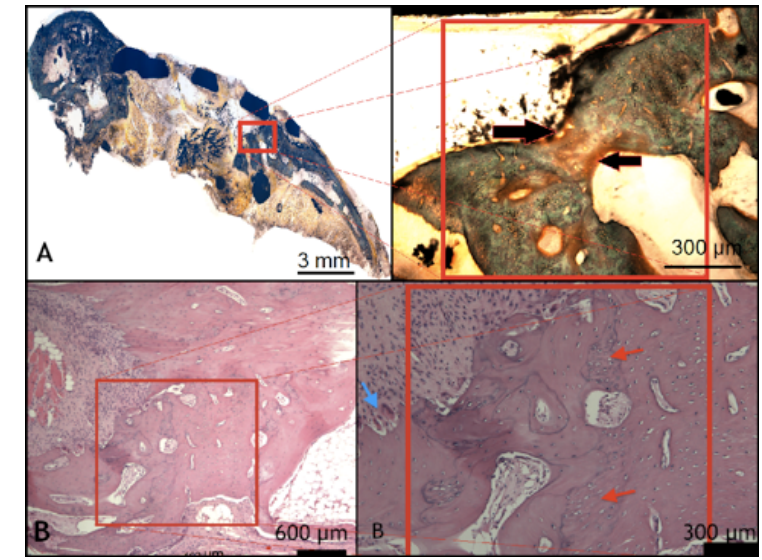

Figure 6. Undecalcified section stained with Goldner's trichrome showing areas of union (red box) between the native bone and the regenerated bone. Figure A shows the newly formed bone at the inferior border of the defect, the red box is of an area of bone union. Image $B$ is a decalcified section of the interface between the newly formed and native bone (scale bar $=600 \mu \mathrm{m}$ ) (marked in red box), the right image is the magnification of the same region (scale bar $=300 \mu \mathrm{m}$ ) which shows presence of mixed lamellar and woven bone (red arrows), reversal lines and macrophages (blue arrow) which demonstrate active remodelling of the newly formed bone.

\subsection{Dynamic Histomorphometry (Bone Calcification Over Time)}

Two of the fluorochrome bone labels were clearly observed, those given at 8 and 11 weeks post surgery (Calcein blue and Alizarin complex). The labels formed concentric lines that were consistent with bone osteons or they appeared as parallel lines indicating a cortical-type pattern of bone formation (Figures 10, 11, 12). Areas of woven bone were also noted in the network-like structure visible with both staining methods (Figure 4). Variable directions of bone deposition were noted in relation

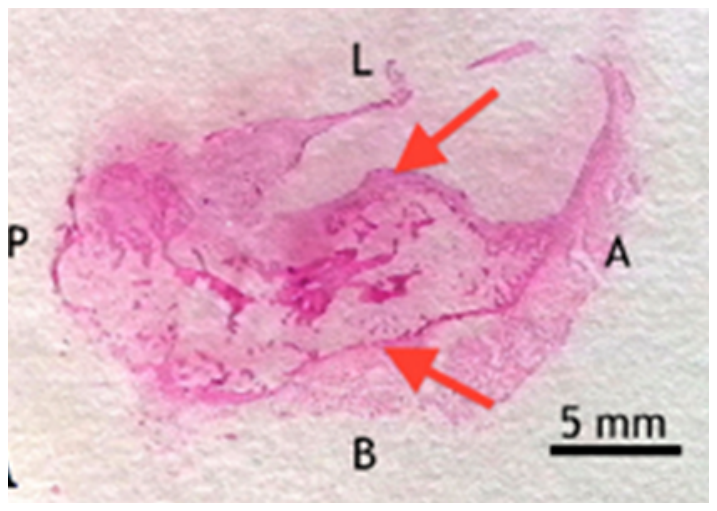

Figure 7 Undecalcified H\&E stained sections of the proximal border of the defect. L, B, P and A refer to lingual, buccal, proximal and anterior walls of the defect respectively. A) Shows the buccal and the lingual cortices (red arrows) of the newly formed bone, (scale bar $=5 \mathrm{~mm}$ ).
Table III. Semi-quantitative scoring for the qualitative assessment of bone regeneration and incorporation of the graft.

\begin{tabular}{ll}
\hline Description & Grade \\
\hline Cortex development & 0 \\
$\quad$ No cortex & 1 \\
One cortex intact & 2 \\
$\quad$ Both cortices intact & \\
\hline Residual implant & 0 \\
$\quad$ No residual implant & 1 \\
$\quad$ Less than 50\% of implant area & 2 \\
$\quad$ Cement remnant > 50\% of implant area & \\
\hline Marrow fibrosis/ Collagen fibres & 0 \\
$\quad$ No marrow spaces & 1 \\
$\quad>5 \%$ occupied with marrow area & 2 \\
$\quad>20 \%$ occupied with marrow area & 0 \\
\hline Inflammatory cells & 1 \\
Less than 20 cells at high power field & 2 \\
$\quad$ One focus $>20$ cells at high power field & \\
$\quad$ Two or more foci &
\end{tabular}

to its location. The calculated mean MAR was 1.92 $\pm 0.5 \mu \mathrm{m} /$ day and $1.1 \pm 0.08 \mu \mathrm{m} /$ day for the regenerated bone and the control side respectively (Table 6).

\subsection{Summary of the Results}

In summary, the areas of bone formation that fully bridged the gap were limited and the observed new bone was throughout the muscle and connective tissue surrounding the cement remnant. The bone displayed a high degree of remodelling with an intricate network of woven bony trabeculae within the cement. The bone was thicker in a bucco-lingual direction and exhibited more marrow and fatty spaces compared to the contra lateral (nonoperated) side. Quantitative histomorphometric assessment showed that the average bone surface area was $21.2 \pm 6 \mathrm{~mm}^{2}$ which was $15.2 \%$ more than for the bone of the contra-lateral control side. On other hand, the calculated percentage of residual cement and the soft tissue or marrow spaces were $20 \pm 12 \%$ and $41 \pm 10 \%$ respectively. The dynamic histomorphometric analysis showed the average mineral apposition rate (MAR) was $1.92 \mu \mathrm{m} /$ day.

\section{Discussion}

This study demonstrated the potential for injecting cement which acted as a bio-scaffold loaded with BMP-7 and seeded with rMSC into a muscle flap for the reconstruction of bony defects in rabbit mandibles. The muscle flap provided the required blood supply for bone bioengineering and acted as a bioreactor for the rMSCs. In this study two possible mechanisms may have contributed to the osteoinduction, the surface microstructure of the injected cement may have promoted both the precipitation of biological apatite and cell adhesion onto the surface of the materials ${ }^{34}$. The microporosity which was less than $5 \mu \mathrm{m}$ in diameter might have enhanced ionic exchange with body fluids $^{35}$. Furthermore, the micropores greatly enlarge the surface area of the material and this 


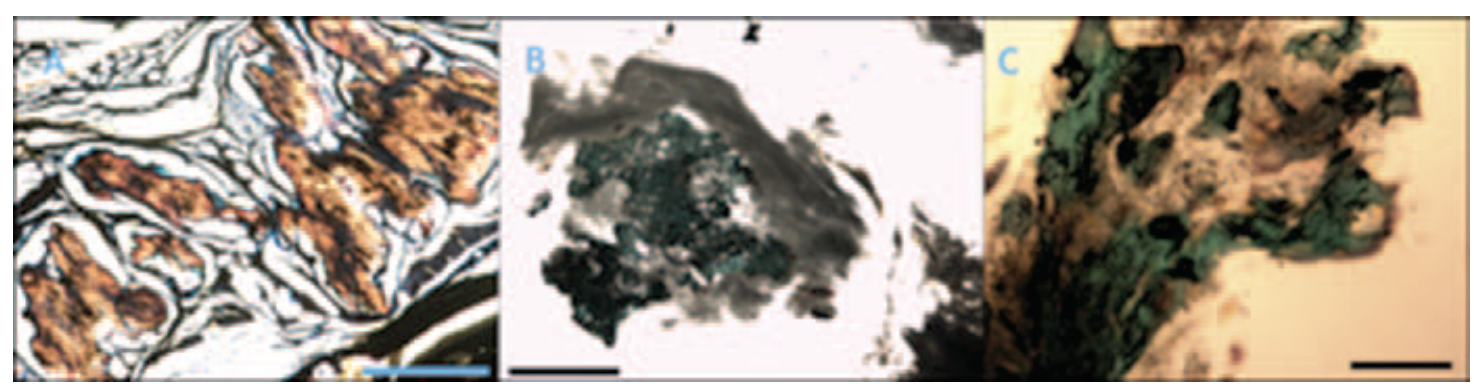

Figure 8 Undecalcified sections (scale bar $=400 \mu \mathrm{m}$ ), stained with Sanderson's-Van Gieson stain $(A)$ showing loose fibrous tissue, and stained with Goldner's trichrome $(B)$ showing black areas representing the residual cement and green areas representing the calcified tissue. C shows areas of calcification (green) present alongside the residual cement (black area).

may have facilitated the adsorption and entrapment of endogenous proteins including protein, the BMP7, which has a high affinity for calcium phosphates $^{36}$. These proteins on the surface of the material could have promoted both the adhesion and differentiation of progenitor cells into osteoblasts. The osteogenic cells attached to this biological apatite layer produced an extracellular matrix composed of collagen, non-collagenous proteins and growth factors including BMP. Secondly, micro particles less than $5 \mu \mathrm{m}$ could have been released around the biomaterial as a result of the dissolution of the inter grains in body fluids. This release of micro particles provoked an inflammatory reaction and the local release of inflammatory cytokines (tumour necrosis factor-alpha, interleukins-6, 10, -8) which stimulated circulating stem cells to differentiate into osteoblastic cells for bone regeneration ${ }^{37,38}$.

Our results showed that the complete bridging of the surgical defect with the newly formed bone was only achieved in some cases. This was partially due to the physical nature of the injected cement that prevented the diffusion of the material at a micro

Table IV. Summary of the average surface area of the regenerated bone in $\mathrm{mm}^{2}$ of the examined slides and the percentage of the newly formed bone in comparison with the contra-lateral non-surgical side.

\begin{tabular}{ccc}
\hline $\begin{array}{c}\text { Case } \\
\text { number }\end{array}$ & $\begin{array}{c}\text { Average } \\
\text { surface area } \\
\left(\mathrm{mm}^{2}\right)\end{array}$ & $\begin{array}{c}\text { Percentage } \\
\text { bone } \\
\text { formation }(\%)\end{array}$ \\
\hline 151 & $20.9 \pm 10.2$ & $113 \pm 5$ \\
152 & $12.3 \pm 3.4$ & $66 \pm 17$ \\
214 & $12.1 \pm 1.2$ & $72 \pm 7$ \\
215 & $10.5 \pm 1.6$ & $59 \pm 11$ \\
216 & $8.3 \pm 0.9$ & $42 \pm 4$ \\
217 & $10.3 \pm 1.5$ & $62 \pm 9$ \\
218 & $47.5 \pm 9.6$ & $137 \pm 27$ \\
239 & $17.0 \pm 9.2$ & $92 \pm 5$ \\
240 & $35.7 \pm 10.2$ & $193 \pm 13$ \\
241 & $37.9 \pm 17.3$ & $199 \pm 20$ \\
\hline Average for & $21.2 \pm 6$ & $103 \pm 60$ \\
experimental & & \\
sides & & \\
Control & $18.4 \pm 2.1$ & \\
\hline
\end{tabular}

level between the fibres of the muscle tissue to reach the surgical defect. Another factor that could have impaired the process of bridging the created defect with the newly formed bone was the bulkiness of the muscle flap. The muscle tissue has obliterated the defect therefore it was physically clinically difficult to ensure that the injected scaffold had reached the surgical bony defect uniformly. In retrospect it might have been useful to reduce the thickness of the masseter muscle before adapting it into the created surgical defect. However, this might have compromised the blood supply to the surgical site. It could be also argued that use of a more bulky muscle flap would provide more osteoprogenitor cells or endogenous growth factors to the grafted site. It has been debated that the amount of muscle and surface area volume ratio would have been a detrimental factor that governs the amount of regenerated bone ${ }^{26}$. It is also important to emphasise that the removed bone with quite thin, about $1 \mathrm{~mm}$ thickness, which added to the complexity of anatomically regenerating the resected segment.

Studies on factors affecting bone regeneration have shown that several important aspects are crucial for this to be achieved successfully including; a

Table V. Summary of the histomorphometry measurements at the surgical site showing the average amounts of regenerated bone, residual cement and soft tissue or marrow spaces.

\begin{tabular}{cccc}
\hline $\begin{array}{c}\text { Case } \\
\text { number }\end{array}$ & $\begin{array}{c}\text { Amount } \\
\text { new bone } \\
\text { regenerated } \\
(\%)\end{array}$ & $\begin{array}{c}\text { Residual } \\
\text { cement } \\
(\%)\end{array}$ & $\begin{array}{c}\text { Soft tissue or } \\
\text { marrow spaces } \\
(\%)\end{array}$ \\
\hline 151 & $33 \pm 9$ & $32 \pm 6$ & $32 \pm 7$ \\
152 & $49 \pm 12$ & $23 \pm 8$ & $31 \pm 16$ \\
214 & $45 \pm 5$ & $9 \pm 8$ & $48 \pm 12$ \\
215 & $22 \pm 6$ & $12 \pm 5$ & $66 \pm 32$ \\
216 & $34 \pm 2$ & $14 \pm 7$ & $50 \pm 5$ \\
217 & $38 \pm 15$ & $30 \pm 9$ & $35 \pm 11$ \\
218 & $47 \pm 11$ & $8 \pm 1$ & $37 \pm 3$ \\
239 & $29 \pm 13$ & $33 \pm 5$ & $34 \pm 32$ \\
240 & $38 \pm 21$ & $22 \pm 4$ & $40 \pm 18$ \\
241 & $36 \pm 14$ & $25 \pm 13$ & $37 \pm 23$ \\
\hline Average & $37 \pm 15$ & $20 \pm 12$ & $41 \pm 10$ \\
& & &
\end{tabular}




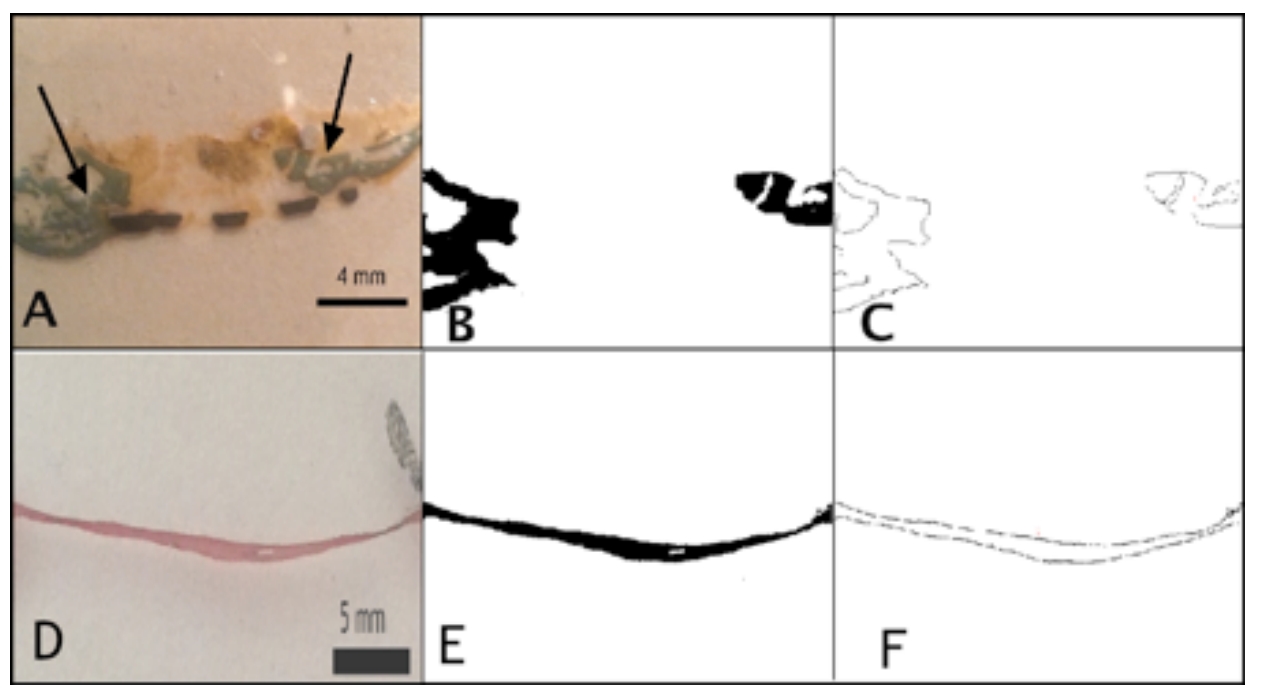

Figure 9 Histomorphometric analysis of the regenerated bone. A) Undecalcified section stained with Goldner's trichrome, the area of bone regeneration is indicated with arrows. B) binary image of the surgical defect and the

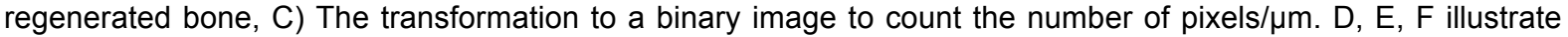
the same steps as in A, B, C for the control (non operated) sides. The calculated surface area of bone at the experimental side was $15.3 \mathrm{~mm}^{2}$ and $18.4 \mathrm{~mm}^{2}$ for the non operated side, (A to $C$ scale bars $=4 \mathrm{~mm}$ and $\mathrm{D}$ to $\mathrm{F}$ scale bars $=5 \mathrm{~mm}$ ).

mechanically stable environment, the presence of adequate vascularity and an intimate contact of the scaffold with native bone ${ }^{39-42}$. In our experiment we injected the bone cement around the bony margins of the defect as well as inside the muscular tissue to ensure direct contact of the cement with bone.

However, the technique of injecting the cement within the muscle tissue was difficult to standardize fully due to the bulkiness of the muscle. Therefore, direct contact between the cement and surrounding native bone could not be confirmed.

We utilised a pedicled muscle flap which acted as a bioreactor for the injected cement and cells and to maintain the vascularity at the surgical site, which is a major challenge in oro-facial reconstruction.

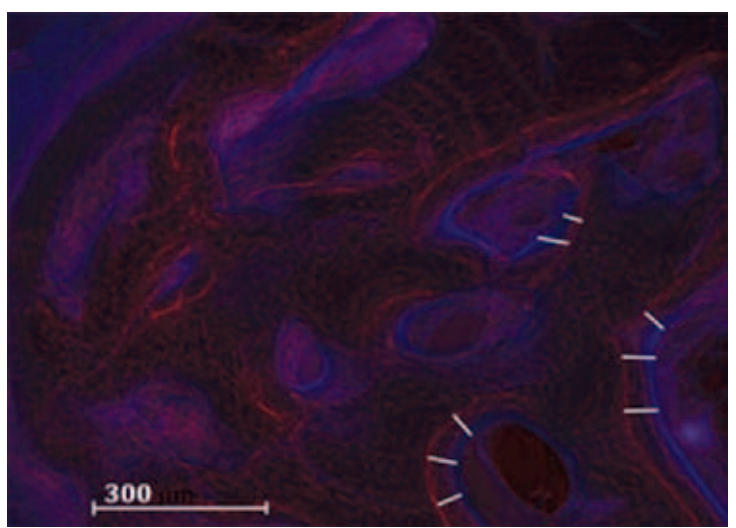

Figure 10. Unstained undecalcified sections to evaluate the rate of mineralization using fluorescent microscopy (Zeiss Axioskop, Germany) and an R/G light filter (HBO 100, LEj, Germany). The image shows calcein blue (red lines) alizarin blue (blue lines) which was given at 8 and 11 weeks, respectively. The distance between the two lines (white bars) indicate the MAR (scale bar $=300 \mu \mathrm{m})$.

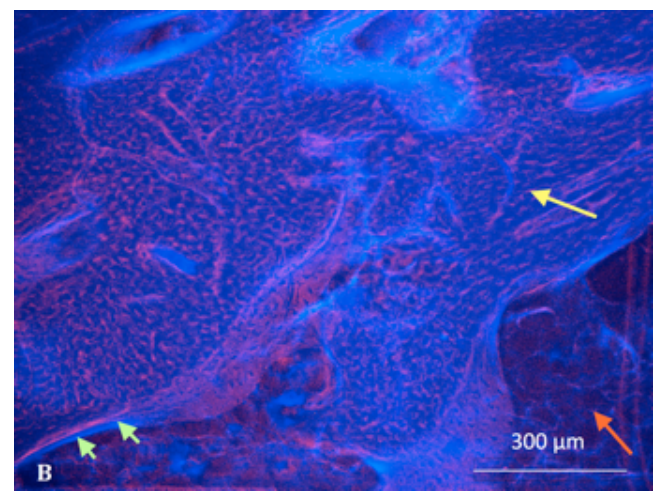

Figure 11 An unstained undecalcified section showing bone regeneration and the pattern of tissue maturation at the experimental side under fluorescent microscopy. The image shows the mature lamellar bone (yellow arrow), the network like structure of woven bone (orange arrow), and the dividing line between different bone (reversal line) (green arrows), (scale bar $=300 \mu \mathrm{m}$ ).

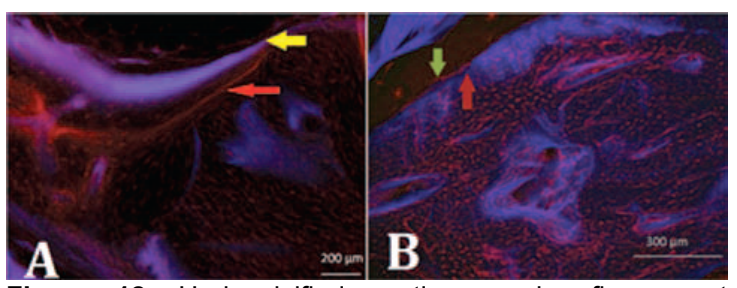

Figure 12. Undecalcified sections under fluorescent microscopy of various regions of the regenerated bone. A) Shows the woven bone superiorly and lamellar bone at the lower end, calcein blue (yellow arrow) located close to the woven bone and the alizarin complexion (red arrow) located close to the lamellar bone confirming the fast bone remodelling rate (scale bar $=200 \mu \mathrm{m}$ ). B) A section of regenerated bone adjacent to the loose fibrous tissue superiorly, the alizarin complexion red line (green arrow) is located next to the loose fibrous tissue and the blue line indicating the calcein blue close to bone deposition (red arrow) (scale bar $=300 \mu \mathrm{m})$. 

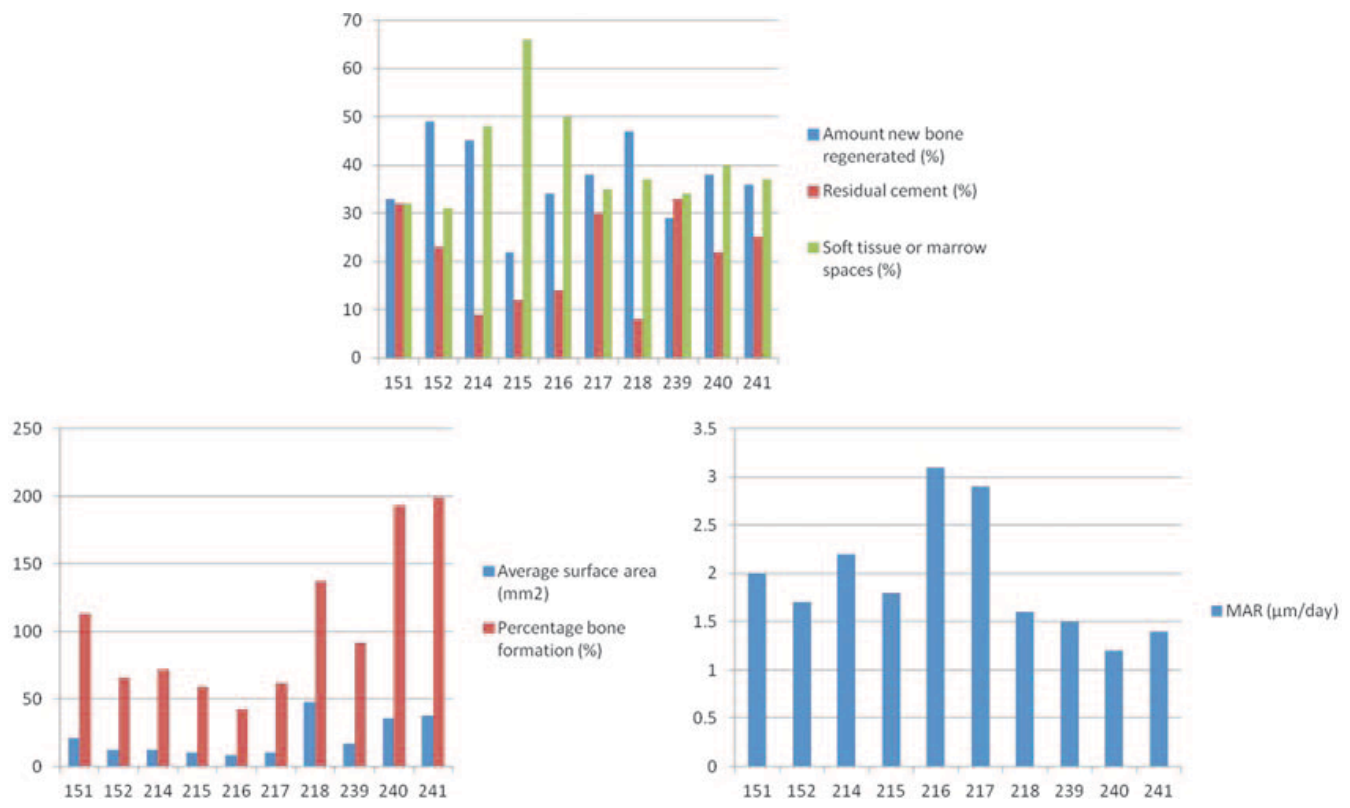

Figure 13. Bar Charts showing the average surface area of the regenerated bone in $\mathrm{mm}^{2}$ of the examined slides and the percentage of the newly formed bone in comparison with the contra-lateral non-surgical side. The histomorphometry measurements at the surgical site showing the average amounts of regenerated bone, residual cement and soft tissue or marrow spaces. The average Mineral Apposition Rate (MAR) of the newly generated bone and the contra-lateral non-surgical control side. x-axis numbers are the identification numbers of the rabbits used in the experiment.

Muscle contraction could have induced bone formation at the periphery of the defect as it has been previously reported ${ }^{43}$. The decalcified sections showed that the newly generated bone displayed a high degree of remodelling with an intricate network of woven bone trabeculae within the CERAMENT TMISPINE SUPPORT. The bone appeared mature and attained a lamellar structure at the periphery, whereas appeared more woven toward the centre. This pattern of bone formation was confirmed by dynamic histomorphometry. In general, the regenerated bone appeared to be thicker in the bucco-lingual direction compared to the non-operated site. The thickness of the removed bone did not exceed $1.5 \mathrm{~mm}$. However, most of the formed bone was either laterally or medially to the created defect.

Table IV. The average Mineral Apposition Rate (MAR) of the newly generated bone and the contralateral non-surgical control side.

\begin{tabular}{lr}
\hline Case number & MAR $(\mu \mathrm{m} /$ day $)$ \\
\hline 151 & $2.0 \pm 0.3$ \\
152 & $1.7 \pm 0.3$ \\
214 & $2.2 \pm 1.2$ \\
215 & $1.8 \pm 0.2$ \\
216 & $3.1 \pm 0.9$ \\
217 & $2.9 \pm 1.2$ \\
218 & $1.6 \pm 0.6$ \\
239 & $1.5 \pm 0.6$ \\
240 & $1.2 \pm 0.4$ \\
241 & $1.4 \pm 0.3$ \\
\hline Average Operated & $\mathbf{1 . 9} \pm \mathbf{0 . 6}$ \\
\hline Average Control & $\mathbf{1 . 1} \pm \mathbf{0 . 3}$ \\
\hline
\end{tabular}

Fluorescent microscopy showed a higher rate of mineral deposition compared to the contra-lateral non-operating control side. This finding is in agreement with micro-CT analysis which showed a less mature trabecular structure as it has been noted in our study.

Decalcified histological assessment showed neither cartilage nor chondrocytes, but only bone regeneration at various levels of maturity. This may suggest an intramembraneous route for bone formation. This is in agreement with other work showing direct intramembraneous bone formation inside calcium phosphate ceramics implanted into extra-skeletal sites ${ }^{19,21}$. It is reasonable to consider that material osteogenesis follows the route of intramembranous ossification initiated by the presence and the differentiation of mesenchymal stem cells into osteoblasts. We acknowledge that it is not possible from the design of this study to separate the mechanism of action of adding rMSCs from the cytokines in inducing bone regeneration. However, the newly formed bone within the muscle flap was closely related to the un-degraded residual cement which has played a major role in inducing bone formation and it is unlikely that rMSCs and BMP alone could have induced bone regeneration within the muscle.

\section{Conclusions}

The study provided a proof of the concept that bone formation can be induced within a pedicled facial muscle flap using injectable cement loaded with BMP-7 and seeded with rMSCS. The regenerated bone did not bridge the surgical gap in all the cases that is not surprising as the injected cement did not diffuse, at a micro level, between the muscle fibres 
and did not reach the proximal and distal bony margins of the created defect. Further development of this approach is required to improve the physical nature of the cement to allow a more comprehensive diffusion of the material within the muscle tissue. Refinements should be considered to guide the injection process and assure that the cement has reached the desired location.

\section{Acknowledgement}

We would like to thank Prof. Edward Odell, King's college London who facilitated the histology assessment of the study. BoneSupport AB, Lund, Sweden kindly supplied the Cerament ${ }^{\mathrm{TM}}$ Spinal Support. The principal investigator was supported by the government of the Kingdom of Saudi Arabia.

\section{References}

1. Y. He, Z.Y. Zhang, H.G. Zhu, W.L Qiu, X.Q. Jiang, W.Guo, Experimental study on reconstruction of segmental mandible defects using tissue engineered bone combined bone marrow stromal cells with three-dimensional tricalcium phosphate. J Craniofac Surg. 18,800 (2007).

2. A.Torroni, Engineered bone grafts and bone flaps for maxillofacial defects: State of the art. J Oral Maxillofac Surg. 67,1121 (2009).

3.D.L. Wheeler, W.F. Enneking, Allograft bone decreases in strength in vivo over time. Clin Orthop Rel Res. 435, 36 (2005).

4. R.E. Guldberg, Spatiotemporal delivery strategies for promoting musculoskeletal tissue regeneration. J Bone Min Res. 24, 1507 (2009).

5. K.FB. Payne, I. Balasundaram, S. Deb, L. Di Silvio, K.F.M. Fan, Tissue engineering technology and its possible applications in oral and maxillofacial surgery. Brit $\mathrm{J}$ Oral Maxillofac Surg. 52, 7 (2014).

6. A.J. Salgado, O.P. Coutinho, R.L. Reis, Bone tissue engineering: State of the art and future trends. Macromolecular Bioscience. 4, 743 (2004).

7. B.C. Kim, J.H. Yoon, B. Choi, J. Lee, Mandibular reconstruction with autologous human bone marrow stem cells and autogenous bone graft in a patient with plexiform ameloblastoma. J Craniofac Surg. 24, E409 (2013).

8. A.S. Herford, M. Ciccio, Recombinant human bone morphogenetic protein Type 2 jaw reconstruction in patients affected by giant cell tumor. J Craniofac Surg. 2, 1970 (2010).

9. M. Ciccio, A.S. Herford, E. Stoffella, G. Cervino, D. Ciccio, Protein-signalled guided bone regeneration using titanium mesh and Rh-BMP2 in oral surgery: A case report involving left mandibular reconstruction after tumor resection. Open Dent J. 6, 51 (2012).

10. A.S. Herford, E. Stoffella, R. Tandon, Reconstruction of mandibular defects using bone morphogenic protein: can growth factors replace the need for autologous bone grafts? A systematic review of the literature. Plast Surg Int. 2011, 165824 (2011).

11. G.J. Meijer, J.D. de Bruijn, R. Koole, C.A. van Blitterswijk Cell based bone tissue engineering in jaw defects. Biomaterials. 29, 3053 (2008).
12. Griffith LG. Emerging design principles in biomaterials and scaffolds for tissue engineering. Ann New York Acad Sci. 961, 83 (2002).

13. L.M. Da Silva, T.T. Sand, R.J. Harman, D.P. Lennon, A.I. Caplan, MSC frequency correlates with blood vessel density in equine adipose tissue. Tissue Eng Part A. 15, 221 (2009).

14. Y.M. Kolambkar, K.M. Dupont, J.D. Boerckel, N. Huebsch, D.J. Mooney, D.W. Hutmacher, R.F. Guldberg, An alginate-based hybrid system for growth factor delivery in the functional repair of large bone defects. Biomaterials. 32, 65 (2011).

15. P.H. Warnke, J. Wiltfang, I. Springer, Y. Acil, H. Bolte, M. Kosmahl M, et al., Man as living bioreactor: Fate of an exogenously prepared customized tissue-engineered mandible. Biomaterials. 27, 3163 (2006).

16. M. Heliotis, K.M Lavery, U. Ripamonti, E. Tsiridis, L. Silvio, Transformation of a prefabricated hydroxyapatite/osteogenic protein-1 implant into a vascularised pedicled bone flap in the human chest. Int J Oral Maxillofac Surg 35, 265 (2006).

17. A. Ayoub, S.R.R Challa, M. Abu-Serriah, J. McMahon, K.. Moos, S. Creanor, E. Odell, Use of a composite pedicled muscle flap and rhBMP-7 for mandibular reconstruction. Int $\mathrm{J}$ Oral Maxillofac Surg. 36, 1183 (2007).

18. H. Kokemueller, S. Spalthoff, M. Nolff,F. Tavassol, H. Essig, C. Stuehmer, K.H. Bormann, M. Rucker, N.C. Gellrich, Prefabrication of vascularized bioartificial bone grafts in vivo for segmental mandibular reconstruction: experimental pilot study in sheep and first clinical application. Int $\mathrm{J}$ Oral Maxillofac Surg. 39, 379 (2010).

19. U. Ripamonti, Osteoinduction in porous hydroxyapatite implanted in heterotopic sites of different animal models. Biomaterials. 117, 31 (1996).

20. Z.J. Yang, H.P. Yuan, W.D. Tong, P. Zou, W.Q. Chen, X.D. Zhang, Osteogenesis in extraskeletally implanted porous calcium phosphate ceramics: variability among different kinds of animals. Biomaterials. 17, 2131 (1996).

21. H.P. Yuan, K. Kurashina, J.D. de Bruijn, Y.B. Li, K. de Groot, X.D. Zhang, Ppreliminary study on osteoinduction of two kinds of calcium phosphate ceramics. Biomaterials. 20, 1806 (1999).

22.P. Habibovic, H.P. Yuan, C.M. van der Valk, G. Meijer, C.A. Blitterswijk, K. de Groot, 3D microenvironment as essential element for osteoinduction by biomaterials. Biomaterials. 26 , 3565 (2005).

23. T. Kokubo, F. Miyaji, H.M. Kim, T. Nakamura, Spontaneous formation of bonelike apatite layer on chemically treated titanium metals. J Am Ceramic Soc 79, 1127 (1996).

24. S. Fujibayashi, M. Neo, H.M. Kim, T. Kokubo, T. Nakamura, Osteoinduction of porous bioactive titanium metal. Biomaterials. 25, 443 (2004).

25. H.P. Yuan, J.D. de Bruijn JD, Y.B. Li, J.Q. Feng, Z.J.Yang, K. Groo, X.D. Zhang, Bone formation induced by calcium phosphate ceramics in soft tissue of dogs: a comparative study between porous alpha-TCP and beta-TCP. Journal of Materials Science: Materials in Medicine. 12, 7 (2001).

26. F. Liu F, R.M. Porter, J. Wells, V. Glatt, C. Pilapil, C.H. Evans, Evaluation of BMP-2 gene- 
activated muscle grafts for cranial defect repair. J Orthop Res. 30, 1095 (2012).

27. R.S. Spitzer, C. Perka, K. Lindenhayn, H. Zippel, Matrix engineering for osteogenic differentiation of rabbit periosteal cells using alphatricalcium phosphate particles in a threedimensional fibrin culture. J Biomed Mat Res 59, 690 (2002).

28. Y. Yamada, S.J. S.J. Boo, R. Ozawa, T. Nagasaka, Y. Okazaki , K.... Hata, M. Ueda, Bone regeneration following injection of mesenchymal stem cells and fibrin glue with a biodegradable scaffold. J Cranio-Maxillofac Surg. 31, 27 (2003).

29. R. Al-Fotawei, K.B. Naudi, M.T. Dalby, E. Tanner, J.D. McMahon, A. Ayoub, Assessment of cellular viability on calcium sulphate/hydroxyapatite injectable scaffolds. J Tissue Eng. 4, 2041731413509645 (2013)

30. R. Al-Fotawei, A. Ayoub, N. Heath, K.B. Naudi, E.Tanner, M.J. Dalby, J. McMahon, Radiological assessment of bioengineered bone in a muscle flap for the reconstruction of critical-size mandibular defect. PLOS One. 9, e107403 (2014).

31. O. Reikeras, F.P. Reinholt, S. Zinoecker, H. Shegarfi, B. Rolstad, Healing of long-term frozen orthotopic bone allografts is not affected by MHC differences between donor and recipient. Clin Orthop Related Res. 469, 1479 (2011).

32. S.M. van Gaalen, W.J.A. Dhert, M.C. Kruyt, H.P. Yuan, F.C. Oner, C.A. van Blitterswijk, A.J. Verbout, J.D.de Bruijn JD, Goat bone tissue engineering: Comparing an intramuscular with a posterolateral lumbar spine location. Tissue Engineering Part A 16, 685 (2010).

33. K.A. Hing, S.M. Best, K.E. Tanner, W. Bonfield, P.A. Revell, Quantification of bone ingrowth within bone-derived porous hydroxyapatite implants of varying density. Journal of Materials Science: Materials in Medicine 10, 663 (1999).

34. D. Le Nihouannen, G. Daculsi, A. Saffarzadeh, O. Gauthier, S. Delplace, P. Pilet, P. Layrolle, Ectopic bone formation by microporous calcium phosphate ceramic particles in sheep muscles. Bone 36, 1086 (2005).

35. G. Daculsi, R.Z. Legeros, M. Heughebaert, I. Barbieux I. Formation of carbonate-apatite crystals after implantation of calcium-phosphate ceramics. Calcified Tissue International. 46,

\section{0 (1990).}

36. K. De Groot, Carriers that concentrate native bone morphogenetic protein in vivo. Tissue Engineering. 4, 337 (1998).

37. J.X. Lu, M.C. Blary, S. Vavasseur, M. Descamps, K. Anselme, P. Hardouin, Relationship between bioceramics sintering and micro-particlesinduced cellular damage. Journal of Materials Science: Materials in Medicine 15, 61 (2004).

38. P. Laquerriere, A. Grandjean-Laquerriere, E. Jallot, G. Balossier, P. Frayssinet, M. Guenounou, Importance of hydroxyapatite particles characteristics on cytokines production by human monocytes in vitro. Biomaterials. 24, 2739 (2003).

39. S. Stevenson, S.E. Emery, V.M. Goldberg, Factors affecting bone graft incorporation. Clinical Orthopaedics and Related Research. 324, 66 (1996).

40.M.A. Feiertag, S.D. Boden, J.H. Schimandle, J.T. Norman, A rabbit model for nonunion of lumbar intertransverse process spine arthrodesis. Spine. 21, 27 (1996)

41. Emery SE, Brazinski MS, Koka A, Bensusan JS, Stevenson S. The biological and biomechanical effects of irradiation on anterior spinal bone-grafts in a canine model. J Bone Joint Surg (Am) 76A, 540 (1994).

42. S.D. Boden, J.H. Schimandle, W.C. Hutton, An experimental lumbar intertransverse process spinalfusion model - Radiographic, histologic, and biomechanical healing characteristics. Spine. 20, 412 (1995).

43. M.P.G. Bostrom P. Aspenberg, C. Jeppsson, E.A. Salvati, Enhancement of bone formation in the setting of repeated tissue deformation. Clin Orthop Related Res 350, 221 (1998). 